\title{
Growth hormone deficiency and replacement in adults
}

\author{
Useful in those with reduced quality of life or bone mineral density
}

Evidence gathered over the past 10 years indicates that growth hormone deficiency in adults is associated with adverse changes in body composition, lipid profile, insulin status, physical performance, bone mineral density, and quality of life. Furthermore, randomised placebo controlled studies indicate that, to varying degrees, growth hormone replacement therapy can reverse these biological changes. Experience has shown that the optimal replacement dose of growth hormone in adults is not only substantially lower than the dose in children but also lower than the dose chosen for the early studies of adult growth hormone replacement. Thus, in future, side effects should be rare. ${ }^{12}$ Recently in many European countries including Britain, adult growth hormone deficiency has become a licensed indication for treatment. However, health economics dictate that we should select those patients most likely to benefit rather than giving a blanket prescription for all. What then are the indications for treatment?

A major problem has been the non-specific nature of the clinical features experienced by patients with growth hormone deficiency, including obesity, mild depression, and fatigue. Greater public awareness of the beneficial effects of replacement may lead to patients with "media onset growth hormone deficiency." In the vast majority of patients, such symptoms are not due to growth hormone deficiency. Unless there is a history of pituitary disease (or suggestive clinical, radiological, or biochemical evidence) such patients should not undergo tests of growth hormone release.

What are the possible benefits of replacement therapy in those patients with proved deficiency? Growth hormone deficiency has been suggested to be responsible for the increased cardiovascular mortality in patients with hypopituitarism, ${ }^{3}$ but it will be some years before we have evidence on whether replacement reduces cardiovascular mortality. The effect of growth hormone replacement on the lipid profile is not all advantageous, ${ }^{4}$ and long term changes in carbohydrate metabolism will probably reflect a compromise between altered body composition, changes in insulin sensitivity, and $\beta$ cell function. ${ }^{5}$ Even if the change in body composition, with a decrease in waist:hip ratio, does represent a potential reduction in a cardiovascular risk factor, the metabolic changes alone are not yet persuasive enough to recommend growth hormone replacement.

Benefit may come in terms of improved quality of life and reduced risk of bone fractures. Impaired quality of life is likely to be a major indication for a trial of growth hormone replacement in individual patients. Those patients who perceive their quality of life to be reduced are most prepared to undergo a trial of replacement, ${ }^{6}$ which suggests that the decision on whom to treat will depend as much on patients as doctors. After nine months of a 12 month study of growth hormone replacement (double blind placebo controlled trial for the first six months and an open trial for the second six months), patients were asked if they wished to continue treatment in the long term once the study was completed. Half of them (48\%) expressed a desire to continue. Compared with the $52 \%$ who did not wish to continue, these patients tended to have more severe deficiency, more distress in terms of energy and vitality at entry into the study, and improved energy after six months of replacement. The patients were not aware of whether they had been given active treatment or placebo during the first six months of the trial, implying that the desire to continue long term replacement did not change significantly after three months' exposure to growth hormone.

These data suggest that adults with proved growth hormone deficiency should be assessed for quality of life (a validated, growth hormone specific, quality of life measure has recently been developed ${ }^{8}$ ). Those patients with severely impaired quality of life should be offered a six month trial of growth hormone replacement. If quality of life is felt to be reasonable, the risk of osteoporosis should be considered. A bone mineral density standard deviation score of -1 is associated with a 2.5fold increase in potential fracture risk. In those with a baseline score of less than -1 , a two year trial of growth hormone replacement therapy should be considered to determine the extent of the response in bone mineral density. However, if the score is greater than -1 , the patient's bone mineral density should simply be monitored.

The response in terms of bone mineral density will differ in adults with childhood onset growth hormone deficiency compared with those with adult onset deficiency. In childhood onset deficiency, bone mineral density improves significantly with six months of treatment ${ }^{9}$ and continues to rise over 18 months. In adult onset deficiency, it does not increase by 12 months, but there is a significant increase at 24 months, which is more pronounced in those with a low baseline standard deviation score. ${ }^{10}$

Our strategy for treating growth hormone deficiency in adults will evolve over the next few years. The enthusiasm for a new replacement therapy is understandable, but we need more information. It will be important to establish unequivocally that adults with growth hormone deficiency who do not receive replacement have more fractures than age matched controls and that replacement normalises the increased fracture rate. The mechanisms behind patients' perceptions of change in quality of life need further exploration. Is the improvement a result of the increased exercise capacity caused by the effect of growth hormone replacement on skeletal muscle or cardiac output? Is it due to modulation of central nervous system neurotransmitters? Does it simply reflect rehydration, correlating with the early increase in extracellular volume, which is characteristically reduced in these patients before treatment? What historical, physical, psychological, or social factors distinguish those patients who deny any benefit from growth hormone replacement? These questions and others need to be answered before the long term role of growth hormone replacement in adults can be defined.

STEPHEN M SHALET Professor of medicine

Department of Endocrinology,

Christie Hospital NHS Trust,

Manchester M20 4BX

1 De-Boer H, Blok G-J, van-der-Veen EA. Clinical aspects of growth hormone deficiency in adults. Endocr Rev 1995;16:63-86.

2 Hansen TB, Vahl N. Jorgensen JOL, Christiansen JS, Hagen C. Whole body and regional soft tissue changes in growth hormone deficient adults after one year of growth hormone treatment: a double-blind, randomised, placebo-controlled study. Clin Endocrinol 1995;43:689-96.

3 Rosen T, Bengtsson B. Premature mortality due to cardiovascular disease in hypopituitarism. Lancet 1990;336:285-8.

4 Eden S, Wiklund O, Oscarsson J, Rosen T, Bengtsson BA. Growth hormone treatment of growth hormone deficient adults results in a marked increase in $\mathrm{Lp}(\mathrm{a})$ and $\mathrm{HDL}$ cholesterol concentrations. Arterioscler Thromb 1993;13:296-301.

5 Beshyah SA, Gelding SV, Andres C, Johnston DG. $\beta$-cell function in hypopituitary adults before and during growth hormone treatment. Clin Sci 1995;89:321-8.

6 Holmes SJ, Shalet SM. Characteristics of adults who wish to enter a trial of growth hormone replacement. Clin Endocrinol 1995;42:613-8.

7 Holmes SJ, Shalet SM. Factors influencing the desire for long term growth hormone replacement in adults. Clin Endocrinol 1995;43:151-7.

8 McKenna SP, Doward LC. Quality of life assessment of adults with growth hormon deficiency. Implications for drug therapy. Pharmacoeconomics 1994;6:434-41.

9 O'Halloran DJ, Tsatsoulis A, Whitehouse RW, Holmes SJ, Adams JE, Shalet SM. Increased bone density after recombinant human growth hormone therapy in adults with isolated $\mathrm{GH}$ deficiency. I Clin Endocrinol Metab 1993;76:1344-8.

10 Johannsson G, Rosen T, Bosaeus I, Sjostrom L, Bengtsson BA. Long-term growth hormone treatment increases bone mineral content and density in patients with adult-onset growth hormone deficiency. 9 Clin Endocrinol Metab (in press). 